Hope College

Hope College Digital Commons

Faculty Publications

8-2013

\title{
Is being "spiritual" enough without being religious? A study of violent and property crimes among emerging adults
}

Sung Joon Jang

Baylor University, Sung_Joon_Jang@baylor.edu

Aaron B. Franzen

Baylor University, franzen@hope.edu

Follow this and additional works at: https://digitalcommons.hope.edu/faculty_publications

Part of the Criminology Commons

\section{Recommended Citation}

Jang, Sung Joon, and Aaron B. Franzen. 2013. "Is Being 'Spiritual' Enough without Being Religious? A Study of Violent and Property Crimes among Emerging Adults." Criminology 51(3):595-627.

This Article is brought to you for free and open access by Hope College Digital Commons. It has been accepted for inclusion in Faculty Publications by an authorized administrator of Hope College Digital Commons. For more information, please contact digitalcommons@hope.edu. 


\section{IS BEING "SPIRITUAL" ENOUGH WITHOUT BEING RELIGIOUS? A STUDY OF VIOLENT AND PROPERTY CRIMES AMONG EMERGING ADULTS*}

\section{SUNG JOON JANG}

Department of Sociology and Institute for Studies of Religion Baylor University

\section{AARON B. FRANZEN \\ Department of Sociology \\ Baylor University}

KEYWORDS: spirituality, religiousness, emerging adulthood, violent crime, property crime

Although prior research has had a tendency to confirm a negative association between religiousness and crime, criminologists have been slow to incorporate new concepts and emergent issues from the scientific study of religion into their own research. The self-identity phrase "spiritual but not religious" is one of them, which has been increasingly used by individuals who claim to be "spiritual" but disassociate themselves from organized religion. This study first examines differences in crime between "spiritual-but-not-religious" individuals and their "religiousand-spiritual," "religious-but-not-spiritual," and "neither-religious-norspiritual" peers in emerging adulthood. Specifically, we hypothesize that the spiritual-but-not-religious young adults are more prone to crime than their "religious" counterparts, while expecting them to be different from the "neither" group without specifying whether they are more or less crime prone. Second, the expected group differences in crime are hypothesized to be explained by the microcriminological theories

* Additional supporting information can be found in the listing for this article in the Wiley Online Library at http://onlinelibrary.wiley.com/doi/10.1111/crim.2011.51. issue-3/issuetoc.

An earlier version of this article was presented at the 2012 annual meeting of the American Society of Criminology, Chicago, IL. The authors are grateful for insightful comments and suggestions of the three anonymous reviewers and the Editor-in-Chief. Direct correspondence to Sung Joon Jang, Department of Sociology, Baylor University, One Bear Place \#97326, Waco, TX 76798 (e-mail: Sung_Joon_Jang@baylor.edu). 
of self-control, social bonding, and general strain. Latent-variable structural equation models were estimated separately for violent and property crimes using the third wave of the National Longitudinal Study of Adolescent Health. The overall results tend to provide a partial support for the hypotheses. Implications for criminology and future research are discussed.

“I'm spiritual but not religious' is a cop-out," says Miller (2012: para. 2), an author on the CNN Belief Blog. Being "especially prevalent in the younger population in the United States," (para. 2) he opined, "the spiritual but not religious reflect the 'me' generation of self-obsessed, truth-is-whatever-you-feel-it-to-be thinking, where big, historic, demanding institutions that have expectations about behavior, attitudes and observance and rules are jettisoned yet nothing positive is put in replacement" (para. 17). Gallup (2003) echoed this portrayal of the increasingly common religious/spiritual self-identity based on a national poll showing "evidence of the focus on self in spirituality" (para. 4) among Americans, which he attributes to "the influence of individualism [that] extends into American spirituality" (para. 6). Although young adults are known to be more religiously unaffiliated than their older counterparts (Pew Research Center, 2010), thus, likely being more crime prone, this identity has never been examined in terms of its implication for criminology.

Criminologists have rarely studied spirituality as a separate concept from religiousness or religion, but this may have been partly because of data constraints (Johnson and Jang, 2010). That is, a crime survey typically contains only a small number of "standard" religion items (e.g., service attendance and religious salience besides denomination) and infrequently, if ever, items reflecting spirituality. In addition, criminologists have been slow in not only collecting new data but also in creatively reinventing existing data to address current issues in the scientific study of religion as they intersect with the interdisciplinary study of crime. We intend to do the latter by focusing on the emergent group of American adults who call themselves "spiritual but not religious" to examine this religious/spiritual identity's relevance for criminology.

To address the issue, we first examine differences in criminal offenses between "spiritual-but-not-religious" individuals and their "religiousand-spiritual," "religious-but-not-spiritual," and "neither-religious-norspiritual" counterparts. Specifically, the "spiritual but not religious" are hypothesized to be at higher risk of committing violent and property crimes than their more religious (i.e., "religious and spiritual" and "religious but not spiritual") peers, whereas they are expected to be different in the risk from the "neither-religious-nor-spiritual" ones. Furthermore, the expected group differences in crime are hypothesized to be explained by general 
theories of crime: self-control, social bonding, and general strain theory. To test the hypotheses, we estimate separate latent-variable structural equation models for violent crimes and property crimes, analyzing the third wave of the National Longitudinal Study of Adolescent Health (Add Health) data collected when respondents were young adults. Given the unfamiliarity of the concept of "spirituality" as distinct from religiousness in criminology, we begin with a discussion of the two concepts.

\section{"SPIRITUAL BUT NOT RELIGIOUS"}

In 1918, Georg Simmel (1997: 20) wrote that in a modernizing culture, people are drawn to mysticism, a highly individualized religious belief or "way of life" because it allows "the fixed definition and delimitation of religious forms to be suspended" when the more "objectively defined" religious life is no longer satisfying. Some people become dissatisfied with institutionalized religion and take on highly individualized religious beliefs. Although the relative importance of the individualized and institutionalized dimensions of religion has ebbed and flowed since Simmel's day, the former dimension has come to be increasingly referred to as "spiritual" as opposed to as "religious," conveying at least partly different meanings (Idler et al., 2003; Miller and Thoresen, 2003; Underwood and Teresi, 2002).

Initially, some theorized that the religious and spiritual dimensions of faith were largely independent of each other (Wuthnow, 1998), but research has uncovered evidence of an overlap between the two. For example, Zinnbauer et al. (1997) found that the term spirituality was most often described in personal or experiential terms, whereas religiousness was used in relation to institutional beliefs and practices, such as church membership or attendance and commitment to the belief system of organized religion. However, based partly on spirituality and religiousness being "modestly" correlated $(r=.21)$, they concluded that the terms are "not fully independent" (p. 561) and thus should not be thought of as mutually exclusive categories but as concepts tapping different dimensions of faith with a fair amount of overlap between them. This conceptualization is further backed by other scholars (Good, Willoughby, and Busseri, 2011; Hill et al., 2000; Schlehofer, Omoto, and Adelman, 2008), and they note that most Americans consider the two concepts as related but distinct from each other (Marler and Hadaway, 2002). For this reason, Dougherty and Jang (2008) found more than half of Americans (57 percent) to be "religious and spiritual" and approximately one quarter ( 27 percent) to be either only "religious" (17 percent) or only "spiritual" (10 percent) with the remainder (16 percent) being neither. 
Thus, recognizing a conceptual distinction as well as an overlap between the "religious" and "spiritual" dimensions, ${ }^{1}$ we treat them as two related constructs (see also Hill et al., 2000; Marler and Hadaway, 2002; Schlehofer, Omoto, and Adelman, 2008; Zinnbauer, Pargament, and Scott, 1999). The religious dimension concerns church-centered beliefs and practices (Wink et al., 2007; Wink and Dillon, 2008), faith that is oriented toward tradition (Pepper, Jackson, and Uzzell, 2010; Saucier and Skrzypinska, 2006), institutional and societal pressures (Zwissler, 2007), and a socially oriented and directed faith (Piedmont, 1999; Schlehofer, Omoto, and Adelman, 2008; Zinnbauer et al., 1997).

The spiritual dimension, however, connotes an individual's search for a connection with the sacred (Piedmont, 1999), a generalized spiritual seeking (Wink and Dillon, 2008; Wink et al., 2007; Wuthnow, 1998), a subjective religious orientation (Saucier and Skrzypinska, 2006), and an emphasis on personal experiences and individuality (Roof, 1993; Zwissler, 2007). It also could imply some nontheistic notion of a higher power (Schlehofer, Omoto, and Adelman, 2008), a faith with an internal source (Fuller, 2001), an interest in mysticism, experimentation with unorthodox beliefs and practices, and negative feelings toward both clergy and churches (Zinnbauer et al., 1997). That is, unlike the religious dimension that is relatively stable in its relation to something institutional in orientation, the spiritual dimension has two different sides to it. One side of being "spiritual" blends well with institutional religious practices, as noted by Good, Willoughby, and Busseri, (2011). The other side is antagonistic to organized religious faith (Garelli, 2007; Zinnbauer et al., 1997), is associated with a feeling of alienation from religion (Roof, 1999), and may be characterized as "deconverting" from something (Harrold, 2006).

How then are we to know whether the term "spiritual," when used, refers to the antagonistic or proinstitutional side? Because it could connote either favorable or unfavorable attitudes toward religion, the meaning can be determined by whether it is used in conjunction with the term "religious" or not (e.g., "spiritual" as well as "religious" or "spiritual" without being "religious"). For this reason, a two-by-two typology is a better approach to operationalizing the concept of "spiritual" rather than spirituality being measured as a continuous variable independent of religiousness (e.g., Giordano et al., 2008; Piedmont et al., 2009). That is, we can ask survey respondents whether they are "spiritual" and whether they are "religious," and then

1. Each dimension can be measured by using items designed to tap an individual's religiousness and spirituality (e.g., Hodge, Andereck, and Montoya, 2007) or by asking an individual to self-rate how religious and how spiritual he or she is (e.g., Dougherty and Jang, 2008; Zinnbauer et al., 1997). This study is based on the latter measurement. 
we can more clearly distinguish discrete categories reflecting "spiritual but not religious," "spiritual and religious," "religious but not spiritual," and "neither."

This typological approach allows for an overlap of the constructs for those respondents who have both an institutional "religious" faith as well as an individually invested "spiritual" approach to faith. More importantly, it can distill out and separate those with a more hostile "spirituality" from those whose "spirituality" is not antagonistic because of their attraction to being "religious." This typology has been used in previous studies (Chatters et al., 2008; Hodge, Andereck, and Montoya, 2007; Marler and Hadaway, 2002; Roof, 1999; Storm, 2009; see Garelli, 2007, for a somewhat expanded form).

To the extent that the four-part typology is not random in such a way that the four groups of individuals systematically differ in propensity for crime, we are led to ask questions for which criminology has no ready answers. How would we rank order the four groups in terms of their probability of criminal offending? Is the emerging group of "spiritual-but-notreligious" individuals more or less likely to commit crime than the others? If that group is more or less likely to commit crime, then why? Criminological theories and research have suggested that, all other things being equal, religious individuals should be less likely to commit crime than their nonreligious counterparts (Baier and Wright, 2001; Johnson and Jang, 2010). However, criminologists have not studied a relationship between criminal offending and being "spiritual," providing little help with hypothesizing the relationship.

\section{RELIGION IN MICROCRIMINOLOGY}

Although criminological research on religion has been conducted at both the macrolevel and the microlevel, this study focuses on the latter because we intend to examine and explain differences in crime among individuals of differential religious self-identification. In fact, Johnson and Jang's (2010: 121) systematic review revealed that "theoretical explanations of the influence of religion on crime have been predominantly social psychological," which they attributed partly to an intellectual climate at the time of the publication of Hirschi and Stark's (1969) "hellfire" study, which generated much research on religion and crime. As a result, microcriminological theories have been applied to explain the effect of religion, particularly individual religiousness, on crime. Johnson and Jang (p. 122, emphasis in original) summarized as follows:

While none of [the] theories focus on religion as a key cause or correlate of crime, they all offer explanations of the religion-crime 
relationship by identifying processes, by which religiosity is expected to decrease the probability of crime. Specifically, religious individuals are less likely to commit crime than their less religious counterparts..., because they are more likely to: (1) fear supernatural sanctions as well as this temporal criminal punishment and feel shame and embarrassment associated with deviance; (2) be bonded to conventional society in terms of attachment, commitment, involvement, and beliefs; (3) exercise high self-control attributable to effective child-rearing by their parents likely to be also religious; (4) have frequent and intimate associations with peers who reinforce conventional definitions and behaviors and become a model for imitation relative to those who do not; and (5) cope with life's strains or stressors and their resultant negative emotions in a legitimate, non-deviant manner. Thus, individual religiosity is expected to be negatively associated with crime.

Because of data constraints (see footnote 4), we incorporate three of the preceding theories (Agnew, 2006; Gottfredson and Hirschi, 1990; Hirschi, 1969) into our explanations for expected differences in crime between the "spiritual but not religious" and three other groups of individuals: "religious and spiritual," "religious but not spiritual," and "neither religious nor spiritual."

Given the conceptual duality of being "spiritual," the spirituality-crime relationship is to be explained by criminological theories in the same way as its religiousness-crime counterpart to the extent that self-claimed spirituality is associated positively with religiousness, connoting subjective religious orientation and personal experience with organized religion. This would be the case with those who claim to be religious as well as spiritual. However, for those who claim to be spiritual but deny being religious, being "spiritual" is likely to refer to experimenting with unorthodoxy and being negative toward religion or even hostile to its rules and authorities. In such a case, the theories would predict a positive association between spirituality and crime. This antagonistic meaning of being "spiritual" may be what those who claim only to be religious (i.e., "religious but not spiritual") have in mind when they disavow being "spiritual" because it is dissonant with their proreligion attitudes.

Taken together, criminological theories would posit that those who are "religious and spiritual" and "religious but not spiritual" should be less likely to commit crime than their "spiritual-but-not-religious" peers. In contrast, those who deny both being religious and spiritual are expected to be less criminal than their "spiritual-but-not-religious" counterparts if their claiming to be "not spiritual" meant a lack of interest in religion as well as experimenting with unorthodox beliefs and practices. If, however, it is intended to emphasize their negative, antagonistic attitudes toward 
religion more than indicating no religious affiliation, then the "neitherreligious-nor-spiritual" individuals might be somewhat more criminal than the "spiritual-but-not-religious" individuals.

Although little criminological work has taken into account self-identified spirituality and religiousness, one notable exception is Giordano et al.'s (2008) life-course study on the effect of religiosity on criminal desistance, where they distinguished between two "dimensions of religiosity": "religious participation" and "spirituality." The former dimension is roughly equivalent to the concept of being "religious" as we discussed previously, but the latter differs from what we referred to earlier as being "spiritual." Their "spirituality" concept is neither discrete nor dualistic in meaning (i.e., antagonistic to institutional religion or not). Furthermore, "spirituality" was "defined as perceived closeness to God" (p. 109) and "measured by feelings of being close to God" (p. 125) that may tap the more orthodox side of being "religious," like one's attachment to God (Pargament, 1997) rather than being "spiritual." This explicit focus on "God" has traditional and orthodox religious undertones (Zinnbauer et al., 1997), thereby potentially excluding the very population of interest here: those identifying as "spiritual but not religious." After all, for Giordano et al. (2008), spirituality is a dimension of religiosity and, thus, is neither conceptually distinct from being "religious" nor the same as being "spiritual" in the sense discussed previously. As a result, the relevance of Giordano et al.'s study to ours is limited, but it is still helpful for our purposes as they pointed out that the private nature of spirituality may not be helpful in the desistance process because, unlike communally connected coreligionists, others are not present to challenge and support them.

Similarly, measuring spirituality "defined as an experiential relationship with God (or Ultimate Transcendence)" with six items, Hodge, Cardenas, and Montoya (2001: 154) found "spirituality" not to be associated with alcohol use, whereas a measure of religiousness was positively associated with the odds of never using alcohol. Another study, however, showed that "spirituality" tended to be positively associated with alcohol use (Hodge, Andereck, and Montoya, 2007). Specifically, based on a cluster analysis of the same six "spirituality" items plus two religiousness items and ANCOVA tests, they found the spiritual-but-not-religious cluster to report higher levels of alcohol use than its neither-spiritual-nor-religious counterpart. Because the two clusters were not different in religiousness, the higher level of alcohol use can be attributed to the part of being "spiritual."

Although these findings about the relationship of spirituality with crime and alcohol use seem to be contradictory to one another, the mixed findings are, perhaps, actually congruent with the characterization of self-claimed spirituality in relation to criminal propensity. As discussed, claiming to be "spiritual" could, in some cases, have a negative association with criminal 
behaviors as it reflects an individual's positive self-esteem, conventional values, and self-transcendent relationship with something sacred in life (e.g., Hodge, Cardenas, and Montoya, 2001; Miller and Thoresen, 2003; Wink et al., 2007). In other cases, however, if it indicates narcissism, unorthodoxy, and antireligious attitudes, then being "spiritual" is likely to be positively associated with antisocial behaviors (e.g., Marler and Hadaway, 2002; Wink et al., 2007; Zinnbauer et al., 1997) and mental disorder (King et al., 2013). As such, we continue our argument that greater specificity is necessary when examining spiritual as well as religious dimensions of beliefs.

In sum, whereas directly linking spirituality and antisocial behavior is a challenge because of the current dearth of extant research, we can extrapolate from what we know of being "spiritual" and existing theories of crime. If some "spiritual" individuals are opposed to organized religion, then they would not reap the same benefit of protection from criminality that is observed for "religious" individuals. They may be less constrained by religious institutions and the connections that come with it. Thus, "spiritualbut-not-religious" individuals do not have the same communal dimension that reinforces prosocial connections with others, unlike their "religiousand-spiritual" counterparts-who are institutionally embedded as well as personally invested in religion - and to a lesser extent, their "religious-butnot-spiritual" peers.

Criminologically speaking, "spiritual-but-not-religious" individuals are likely to be exposed to lower levels of control (Gottfredson and Hirschi, 1990; Hirschi, 1969) and higher levels of strain (Agnew, 2006) compared with their "religious" peers. In contrast, whether "spiritual-but-notreligious" individuals are more or less likely to be criminal than their "neither-religious-nor-spiritual" peers depends on what they mean when they claim to be "spiritual" because they both are "not religious." Thus, we test between these two alternative hypotheses.

\section{CRIME AND DEVIANCE IN EMERGING ADULTHOOD}

Emerging adulthood refers to "the period from the late teens through the twenties, with a focus on ages 18-25" (Arnett, 2000: 469). According to Arnett (2005: 239, italics added for emphasis), emerging adulthood is "the age of identity exploration ... instability... feeling in-between, neither adolescent nor adult" and "the most self-focused age of life." These features imply potentially negative outcomes because it could become a time of narcissism, unorthodoxy, and "innovation" (Merton, 1938), as well as of low self- and social control relative to full-fledged adulthood. 
Despite their declining pattern, crime rates are still relatively high during emerging adulthood (Laub and Sampson, 2003), and criminologists have found the variables of control and strain to explain criminal behaviors during this period (Piquero et al., 2002). For example, Sampson and Laub $(1993,1996)$ and Laub and Sampson (2003) found measures of adult social bonds, such as marital attachment, job stability, and military service, to have turning point effects in emerging adulthood (see also Uggen, 2000). More recently, Jang and Rhodes (2012) found that low self-control and variables of general strain theory explain violent and property crimes among emerging adults while controlling for social bonding and social learning variables.

Emerging adulthood is also a unique period in life when religious beliefs and practices are in flux. For example, Smith $(2005,2009)$ found a highly individualistic belief "system," likely related to "spirituality" independent of a religious community, to be held in adolescence and to persist into the emerging adult years. In a twin study, Koenig, McGue, and Iacono (2008) showed that religiousness, especially church attendance, decreases with age for emerging adults. Similarly, finding a reduction primarily in religious practices, Uecker, Regnerus, and Valler (2007) reported that irreligious teens tend to solidify their irreligion during emerging adulthood, who are likely to then become "neither religious nor spiritual."

\section{HYPOTHESES AND THEORETICAL MODEL}

This study tests the following hypotheses, focusing on violent and serious property offenses because social group differences (e.g., sex, race, and class differences) tend to be minimal for nonserious, trivial offenses.

Hypothesis 1: Spiritual-but-not-religious individuals are more likely to commit crimes than their "religious" counterparts, whether "spiritual" or not, whereas they are expected to be different in criminal offending from the neither-religious-nor-spiritual individual.

Hypothesis 2: The expected differences in criminal offending are likely to be explained by group differences in religious involvement as well as by the variables of self-control, social bonding, and general strain theories.

To test these hypotheses, latent-variable structural equation models were constructed. The key exogenous variables are three religious/spiritual dummy variables with the spiritual-but-not-religious group as the reference category, and a latent construct of violent or property crimes is the 
ultimate endogenous variable. First, controlling for sociodemographic variables, we estimate a baseline model to establish relationships among the three dummy variables and the latent variable of crime, separately for violent and property offenses. Then, we add six variables, five latent and one manifest, one at a time (models 1 to 6) and then all together (full model), to determine whether the addition changes not only the size but also the significance of the initially estimated relationship between the key exogenous and the ultimate endogenous variables.

\section{METHODS}

\section{DATA}

The current data come from the restricted-use sample of the National Longitudinal Study of Adolescent Health (Add Health), a nationally representative survey of more than 20,000 students, all of whom were in grades 7 through 12 when the first wave was collected during the 1994-1995 school year. Add Health contains an exhaustive array of survey items measuring the respondents' social, economic, psychological, and physical well-being, including an extensive battery of questions asking about delinquency and drug use. Respondents were selected using a multistage, stratified, schoolbased cluster sampling procedure. Eighty high schools, drawn from the Quality Education Database, were stratified by region, urbanicity, sector, racial composition, and size. Attempts were made to match each of these 80 schools with a feeder school, usually a middle school or junior high school. In total, 52 feeder schools were added to the sample of schools, resulting in a sample of 132 schools.

From September 1994 through April 1995, all available students in the 132 schools $(n=90,118)$ completed an In-School Survey. A representative sample of these students $(n=20,745)$ then participated in the In-Home Interview at wave 1 using laptop computers, headphones, and audio recordings to encourage accurate and honest answers to many of the survey's most personal questions. Wave 2 data were collected from those who had not yet graduated from high school $(n=14,738)$ from April through August 1996. Wave 3 was collected in 2001-2002 when the respondents were emerging adults, 18-28 years of age. In total, 1,507 partners of the original sample were added, resulting in a sample size of 15,197 . Finally, wave 4, collected in 2007-2008, has a sample size of 15,701 (see Harris et al., 2009, for details on sampling design).

We focus on the third wave: the only survey that included the two key items of self-identified religiousness and spirituality needed to construct our typology. 


\section{MEASUREMENT}

The religious/spiritual identity variable was created using two self-rated items. One regards religiousness ("To what extent are you a religious person?") and the other spirituality ("To what extent are you a spiritual person?"). Each question was answered based on a 4-point scale: not at all $(=0)$, slightly $(=1)$, moderately $(=2)$, and very religious/spiritual $(=3)$. These categories were dichotomized by combining the first two responses into "not religious/spiritual" and the other two into "religious/spiritual" to construct a $2 \times 2$ typology table that consists of four self-identity categories: religious and spiritual, religious but not spiritual, spiritual but not religious, and neither religious nor spiritual. A system of dummy variables was created, and three categories were included in the subsequent analysis with the spiritual-but-not-religious group, which is of our key interest in comparison with the others, as the reference category.

The first explanatory variable, religious involvement, is a latent construct that has four indicators-religious service attendance, participation in nonservice religious activities, religious salience (i.e., perceived importance of religious faith), and frequency of prayer (see table S.1 in the online supporting information for details $\left.{ }^{2}\right)$, all of which have been found to be negatively associated with crime (Johnson and Jang, 2010). An exploratory factor analysis of the four indicators generated a one-factor solution with high loadings, ranging from .55 to .80 , with a high Cronbach's alpha (.80).

A latent variable of low self-control (Gottfredson and Hirschi, 1990) was measured by two items asking about the respondent's tendency of risk-taking and little thought for the future, ${ }^{3}$ whereas that of attachment to parents, one of two social bonding variables (Hirschi, 1969), was operationalized by three indicators: feeling close to parents, parents being warm and loving, and enjoying doing things with parents. An exploratory factor analysis revealed that the three have high loadings $(.82, .87$, and .84$)$ and that they were found to have an excellent interitem reliability $(\alpha=.88)$.

2. Additional supporting information can be found in the listing for this article in the Wiley Online Library at http://onlinelibrary.wiley.com/doi/10.1111/ crim.2011.51.issue-3/issuetoc.

3. The content validity of our low self-control measure is limited in that it operationalizes only two of the six "elements of self-control" (Gottfredson and Hirschi, 1990: 89, emphasis in original): "exciting, risky, or thrilling" and "little skill or planning." Because low self-control is to be measured by tapping all six dimensions, our measurement is likely to have resulted in false positives (e.g., "risk takers" who have high risk tolerance but not low self-control or respondents with attention deficit disorder who are poor at planning but have high self-control). Positively put, as a result, our test is deemed conservative with respect to the relationship between low self-control and crime to the extent that false positives weaken the relationship. 
The other social bonding variable, commitment to conventional activities, is an index of four items asking whether the respondent was attending or enrolled in school, had received any vocational education or job training, was working for pay for at least 10 hours a week, and/or was serving in the full-time active-duty military when the survey was conducted. Although each item was measured as a dichotomous variable $(0=$ no, $1=$ yes $)$, all of them are measures of adult social bonds that Sampson and Laub (1993) suggested in their age-graded theory of informal social control. ${ }^{4}$

The last two explanatory variables come from Agnew's (2006) general strain theory. Among various types of strain, this study focused on criminal victimization, one of the most criminogenic strains for adults, modeling it as a latent construct with an indicator of vicarious victimization ("saw someone shoot or stab another person") and six of experienced victimization (e.g., being pulled a knife or gun on, shot, stabbed, or beaten up) during the 12 months prior to the survey. An exploratory factor analysis showed that the seven indicators were loaded on a common factor with moderateto-high loadings, ranging from .40 to .66 , and a relatively good interitem reliability $(\alpha=.70)$. Another latent variable measures negative emotions with six items of state depression (i.e., depressive mood and malaise during the last week prior to survey) and had generally high factor loadings and Cronbach's alpha (.80). ${ }^{5}$

Next, two latent endogenous variables of crimes were constructed using three items of violent crimes and four items of property crimes committed during the last 12 months prior to the survey. The indicators of violent crime measure how often the respondent engaged in armed robbery, physical fights, and assault, whereas those of property crime tap the frequency of vandalism, theft (two items involving something worth more than $\$ 50$ and less than $\$ 50)$, and burglary $(0=$ never, $1=1$ or 2 times, $2=3$ or 4 times, $3=5$ or more times). Whereas the latter indicators have relatively high loadings, ranging from .50 to .72 , with an acceptable reliability $(\alpha=$ $.67)$, the former have loadings mixed in size $(.37, .74$, and .46) with a low reliability $(\alpha=.44)$. This might reflect a lack of versatility of violent crimes relative to property crimes.

4. We initially included in our model a variable of Akers's (1998) social learning theory: peer drinking, including binge drinking. However, in response to the Editorin-Chief's and the reviewers' concerns about the measure being limited to drinking and based on the respondent's perception of peer deviance rather than peerreported deviance, we removed the social learning variable, and we estimated a model including the variable as well (see footnote 9).

5. Whereas anger tends to have greater construct validity than nonangry emotions (Agnew, 2006), we could not include the emotion in the analysis because the third wave of Add Health data do not contain items of state anger. 
Sociodemographic variables were constructed for statistical control: race $(0=$ non-White, $1=$ White $)$, age (at the time of survey), sex $(0=$ male, $1=$ female), education (whose response categories range from $6=6$ th grade to $22=5$ or more years of graduate school; see table S. 1 in the online supporting information), and marital status $(0=$ never married, divorced, separated, widowed, or in marriage-like relationship; $1=$ married). In addition, a methodological control was constructed that measures whether anyone besides the respondent and the interviewer was present $(=1)$ or not $(=0)$ when the survey was being conducted to adjust for any reporting bias caused by reactivity.

Finally, to control for the respondent's religious affiliation, we created a variable similar to Steensland et al.'s (2000) RELTRAD. Our modified RELTRAD assigns respondents to one of nine religious affiliation groups: evangelical Protestant, mainline Protestant, Black Protestant, Catholic, Jewish, Mormon, other religion, no religious affiliation, or unknown. Those who said they were "just Christian" or "just Protestant" and those who did not know their religious affiliation were sorted into the evangelical Protestant, mainline Protestant, or Black Protestant categories according to racial backgrounds and "born again" self-identification. If we still could not classify the respondent, then they were coded as "unknown."

\section{ANALYTIC STRATEGY}

To test our hypotheses, we used Mplus 7 (Muthén and Muthén, 19982012), a structural equation modeling (SEM) software that enables the analysis of "complex survey" data like the Add Health. The latent-variable SEM approach tends to generate more valid and reliable results than other methods (e.g., path analysis) because it allows controlling for measurement errors. Latent-variable modeling also is suitable to test our hypotheses, where most concepts are abstract and thus are not directly observable. Furthermore, Muthén's (1983) "general structural equation model" and its full information maximum likelihood (FIML) estimation, incorporated into Mplus, allow not only for continuous but also for dichotomous and ordered polytomous variables to be indicators of latent variables, particularly when the variables are skewed. Because our measures of offending are ordered categorical variables, we employed the estimator of MLR: "maximum likelihood parameter estimates with standard errors ... that are robust to non-normality and non-independence of observations" (Muthén and Muthén, 1998-2012: 484). We also used FIML to treat missing data (Baraldi and Enders, 2010; Graham, 2009). Finally, for data-model fit assessment, we focus on joint criteria using three types of fit index (Hu and Bentler, 1999)incremental (comparative fit index [CFI]), absolute (standardized rootmean-squared residual [SRMR]), and parsimonious (root-mean-squared 
error of approximation [RMSEA]) - rather than relying on any one of them. Specifically, a model is determined to have a good fit to data if one of two joint criteria, $(\mathrm{CFI} \geq .96$ and $\mathrm{SRMR} \leq .09)$ or $(\mathrm{SRMR} \leq .09$ and RMSEA $\leq .06)$, is met.

\section{RESULTS}

Table 1 presents descriptive statistics of variables included in the analysis. It shows that the current sample $(n=14,322)$ is 67.6 percent White, 49.2 percent female, and 16.4 percent married. ${ }^{6}$ The respondents were, on average, 21.8 years of age with the youngest and the oldest being 18 and 28, respectively, whereas the mean of their highest education was approximately 1 year of college completed (13.072). Interestingly, although approximately one quarter of the total sample (26.8 percent)-"none" (22.0 percent) or "affiliation unknown" (4.8 percent)—reported no religious affiliation, 43.8 percent of the sample called themselves "neither religious nor spiritual." This finding indicates that reporting religious affiliation is one thing, but it is another to self-identify as "religious" and/or "spiritual." Also, as anticipated, we found the percentage of the "neither religious nor spiritual" to be higher than what Dougherty and Jang (2008) reported for a general population of adults (44 percent vs. 16 percent), which is consistent with previous findings: a general increase of religious "nones" among young adults (Baker and Smith, 2009), and they become stable affiliates as they age (Lim, MacGregor, and Putnam, 2010). ${ }^{7}$ However, the percentage of the spiritualbut-not-religious category was about the same (11 percent vs. 10 percent), whereas both "religious" groups were found to be smaller, whether "spiritual" (38 percent vs. 57 percent) or not (7 percent vs. 17 percent).

6. The current sample consists of only those respondents enrolled in grades 7-12 during 1994-1995 (i.e., wave 1), for whom the Add Health provides sampling weight (GSWGT3_2) to be used in cross-sectional analysis (Chantala, 2006). As a result, 875 of the 15,197 respondents who participated in the third survey could not be included. Also, as anticipated, a relatively small percentage of the emerging-adult respondents was married at the time of survey.

7. In addition, there are two potential methodological reasons for why comparisons with the Baylor Religion Survey (BRS) data, which Dougherty and Jang (2008) analyzed, differ from those of the Add Health. First, the BRS does not have nearly the same number of respondents in the same age category as the Add Health for good comparisons as there is reason to think a cohort effect exists (Marler and Hadaway, 2002). Second, more importantly, this might have been, in part, an artifact. Specifically, the Add Health asks the religious/spiritual questions immediately after one another, more clearly juxtaposing the two and implying that they are not the same concepts. The BRS, however, presents the self-rated religiousness and spirituality questions at different points in the survey, decreasing the perception that they are conceptually distinct. So we believe that the Add Health items are more reliable for constructing our $2 \times 2$ typology than the BRS. 


\section{Table 1. Descriptive Statistics of Variables Analyzed and Group Mean Comparisons ${ }^{\text {a }}$}

\begin{tabular}{|c|c|c|c|c|c|c|c|}
\hline Variables & Mean & (SD) & Minimum & Maximum & $\begin{array}{c}\text { SBNR } \\
\text { vs. RAS }\end{array}$ & $\begin{array}{c}\text { SBNR } \\
\text { vs. RBNS }\end{array}$ & $\begin{array}{c}\text { SBNR } \\
\text { vs. NRNS }\end{array}$ \\
\hline Race (White) & .676 & $(.498)$ & .000 & 1.000 & $.103^{*}$ & $.104^{*}$ & -.003 \\
\hline Age & 21.822 & (1.764) & 18.000 & 28.000 & .123 & .206 & $.188^{*}$ \\
\hline Sex (Female) & .492 & $(.499)$ & .000 & 1.000 & -.022 & -.029 & $.065^{*}$ \\
\hline Education & 13.072 & $(1.965)$ & 6.000 & 22.000 & .057 & $.548^{*}$ & $.553^{*}$ \\
\hline Married & .164 & $(.375)$ & .000 & 1.000 & $-.092^{*}$ & $-.084^{*}$ & -.015 \\
\hline Third Person Present & .233 & $(.420)$ & .000 & 1.000 & .003 & -.017 & -.022 \\
\hline \multicolumn{8}{|l|}{ Religious Affiliation } \\
\hline $\begin{array}{l}\text { Evangelical } \\
\text { Protestant }\end{array}$ & .223 & $(.396)$ & .000 & 1.000 & $-.172^{*}$ & $-.098^{*}$ & .017 \\
\hline Mainline Protestant & .104 & $(.300)$ & .000 & 1.000 & $-.020^{*}$ & -.026 & $-.028^{*}$ \\
\hline Black Protestant & .101 & $(.343)$ & .000 & 1.000 & $-.101^{*}$ & $-.055^{*}$ & .009 \\
\hline Catholic & .237 & $(.435)$ & .000 & 1.000 & -.004 & $-.128^{*}$ & -.027 \\
\hline Jewish & .008 & $(.084)$ & .000 & 1.000 & .009 & -.010 & .005 \\
\hline Mormon & .009 & $(.093)$ & .000 & 1.000 & -.009 & .003 & .002 \\
\hline Other religion & .050 & $(.214)$ & .000 & 1.000 & $.024^{*}$ & $.041^{*}$ & $.053^{*}$ \\
\hline None & .220 & $(.402)$ & .000 & 1.000 & $.241^{*}$ & $.238^{*}$ & $-.063^{*}$ \\
\hline $\begin{array}{l}\text { Affiliation } \\
\text { unknown }\end{array}$ & .048 & $(.214)$ & .000 & 1.000 & $.032^{*}$ & $.035^{*}$ & $.032^{*}$ \\
\hline \multicolumn{8}{|l|}{$\begin{array}{l}\text { Religious/Spiritual } \\
\text { Identity }\end{array}$} \\
\hline $\begin{array}{c}\text { Religious and } \\
\text { spiritual }\end{array}$ & .379 & $(.489)$ & .000 & 1.000 & - & - & - \\
\hline $\begin{array}{l}\text { Religious but not } \\
\text { spiritual }\end{array}$ & .068 & $(.248)$ & .000 & 1.000 & - & - & - \\
\hline $\begin{array}{l}\text { Spiritual but not } \\
\text { religious }\end{array}$ & .115 & $(.315)$ & .000 & 1.000 & - & - & - \\
\hline $\begin{array}{c}\text { Neither religious } \\
\text { nor spiritual }\end{array}$ & .438 & $(.492)$ & .000 & 1.000 & - & - & - \\
\hline Religious Involvement & -.050 & $(.792)$ & -1.166 & 2.223 & $-.824^{*}$ & $-.460^{*}$ & $.303^{*}$ \\
\hline Low Self-control & 2.822 & $(.816)$ & 1.000 & 5.000 & $.074^{*}$ & -.017 & $-.121^{*}$ \\
\hline Attachment to Parents & .001 & (.898) & -4.722 & .881 & $-.214^{*}$ & $-.140^{*}$ & -.014 \\
\hline $\begin{array}{l}\text { Commitment to } \\
\text { Conventional } \\
\text { Activities }\end{array}$ & .198 & $(.202)$ & .000 & 1.000 & $-.028^{*}$ & $.032^{*}$ & $.025^{*}$ \\
\hline Criminal Victimization & .026 & $(.095)$ & .000 & 1.000 & .015 & .015 & .019 \\
\hline State Depression & .486 & $(.495)$ & .000 & 3.000 & $.046^{*}$ & $.054^{*}$ & $.083^{*}$ \\
\hline Violent Crimes & .082 & $(.248)$ & .000 & 3.000 & $.008^{*}$ & .000 & -.004 \\
\hline Property Crimes & .072 & $(.230)$ & .000 & 3.000 & $.051^{*}$ & $.044^{*}$ & $.032^{*}$ \\
\hline
\end{tabular}

NOTE: The number of observations for each variable analyzed range from 14,087 to 14,322 , and all analyses were weighted and corrected for survey design.

ABBREVIATIONS: NRNS = "neither religious nor spiritual"; RAS = "religious and spiritual"; RBNS = "religious but not spiritual"; SBNR = "spiritual but not religious"; SD = standard deviation.

${ }^{a}$ The tests of difference in group means were based on the coefficients of three dummy variables being RAS, RBNS, and NRNS (see the last three columns), regressed on each variable with SBNR being the omitted category. $* p<.05$ (two-tailed test). 


\section{GROUP COMPARISONS}

Table 1 also reports results from comparing means between the "spiritual but not religious" (SBNR) and each of the other three groups (see the last three columns): "religious and spiritual" (RAS), "religious but not spiritual" (RBNS), and "neither religious nor spiritual" (NRNS). We estimated group-mean differences in terms of the structural relationships between dummy variables representing the three groups and each variable listed in the table, where a positive (negative) coefficient indicates the reference group's (i.e., SBNR's) mean being larger (smaller) than a comparison group's mean.

Significant group differences tend to be consistent with what we discussed previously: SBNR emerging adults are likely to be at higher risk for criminal offending than their RAS and RBNS peers, whereas they are expected to be at higher risk in some aspects but at lower risk in others than their NRNS counterparts. At the time of survey, for example, the SBNR were less likely than the "religious"-RAS (-.092) and RBNS (-.084) - to have been married, which tends to decrease crime in emerging adulthood, particularly when marriage is cohesive (Sampson and Laub, 1993). In contrast, as expected, the SBNR-NRNS comparison results were mixed: The SBNR were not different from the NRNS (-.015) in marital status, but differences were found in social class (.553), being higher in terms of education. The SBNR also reported higher grade or year of regular school completed than the RBNS (.548), although not the RAS (.057). ${ }^{8}$ These demographic differences between the SBNR and the others tend to be similar to previous findings based on a national sample of American adults (Dougherty and Jang, 2008).

Furthermore, interestingly, the SBNR respondents were more likely than their RAS and RBNS peers to report affiliations other than Christian denominations as their "present religion," such as Islam, Eastern religion, paganism, or New Age spirituality, whereas not surprisingly, they were less likely to be either Protestant or Catholic. They also were more likely to have "unknown" religion as well as being "none," atheistic, or agnostic than their "religious" counterparts, whereas there was no difference in terms of affiliation with Jewish and Mormon religions. Similarly, the SBNR were more likely to have "other" (.053) or "unknown" religion (.032) than the NRNS, and they were less likely to be "none" (-.063). When taken together,

8. In addition, the SBNR respondents in the sample were more likely to be White than their "religious" counterparts, whether they call themselves "spiritual" (.103) or not (.104), whereas they were not significantly different from the NRNS (-.003). However, the SBNR were older (.188) and more likely to be female (.065) than the NRNS. 
the SBNR seem to be "not religious" with respect to the Protestant or the Catholic religion but tend to be open or favorable to non-Christian, nonWestern, postmodern religion compared with the others (Fuller, 2001).

More importantly, the SBNR were found to be at higher risk for criminal offending than the RAS and RBNS in terms of the explanatory variables, while their comparisons with the NRNS generated mixed findings. First, the SBNR were less likely to be religiously involved than the RAS and RBNS (-.824 and -.460), although more likely than the NRNS (.303). This confirms that the SBNR were "not religious" if it concerns the Protestant or the Catholic denomination, but they were found to be more religious than the NRNS as long as it is not the Christian religion, although they are still less involved in religion than the RAS and RBNS.

Next, the SBNR respondents were at higher risk of criminal offending in terms of low self-control and negative emotional state, and they were less constrained by adult social bonds compared with their "religious" counterparts. Specifically, they reported a significantly higher mean of low self-control than the RAS (.074), although not the RBNS (-.017), and they were found to have experienced depressive mood and malaise more often during the last week prior to the survey than both "religious" groups (.046 and .054), which is consistent with a previous study (King et al., 2013). Also, the SBNR were less likely to be attached to their parents than the RAS (-.214) and the RBNS (-.140), whereas they were less committed to conventional activities than the RAS (-.028) but more so than the RBNS (.032). In contrast, the SBNR were at a lower risk of criminal offending than the NRNS in terms of low self-control (-.121) and commitment to conventional activities (.025), but they were at a higher risk with respect to state depression (.083). However, the SBNR were not different in criminal victimization from the others.

Finally, consistent with the preceding group differences in the correlates and causes of crime, the SBNR were found to have committed crimes more often than the other groups during the last 12 months prior to the survey, which was more pronounced in property than in violent crimes. Specifically, the SBNR reported higher levels of violent criminal offending than the RAS (.008), although not compared with the RBNS (.000) and the NRNS (-.004). On the other hand, the SBNR committed property crimes more often than the RAS (.051), the RBNS (.044), and the NRNS (.032).

\section{Measurement and Structural Models}

Before interpreting results from estimating our model, we need to assess the model's overall fit to the current data. First, both models of violent and property crimes are found to have a good fit, meeting one of Hu and Bentler's (1999) joint criteria, with standardized root-mean-squared 
residuals (SRMRs) being smaller than .090 (ranging from .008 to .023 in the violent crime model and from .011 to .023 in the property crime model) and root mean square error of approximations (RMSEAs) smaller than .060 (from .013 to .033 and from .017 to .031), despite comparative fit indices (CFIs) (from .865 to .973 and from .885 to .965) mostly not reaching the minimum cutoff (.960). Overall, the model fit is adequate, which supports interpreting the results.

Beginning with the latent variables' measurement models, we found most of their indicators to have moderate-to-high loadings in both the violent and property crime models, ranging from .362 to .867 as shown in table 2 (see the top panel), which also presents correlations among the explanatory variables (see the bottom panel of table 2). Most correlations were significant in the expected direction.

Table 3 shows the unstandardized coefficients of the structural models of violent crimes, estimated first with no additional explanatory variables (baseline model) and then with one additional explanatory variable at a time (models 1 to 6 ) as well as all six of them simultaneously (full model). Significant coefficients of sociodemographic variables are mostly in the expected direction as race (White), age, sex (female), education, and being married are all negatively associated with violent crimes. In contrast, the methodological control (third person present) and the dummy variables of religious affiliation (RELTRAD) were found to be not significant with one exception: Mormon respondents were less likely to commit violent crime than their evangelical Protestant peers in the baseline (-.013) and all but one intermediate models $(-.013$ or -.017$)$, though not in the full model $(-.015)$.

The baseline model provides partial support for the first hypothesis. The RAS dummy variable was found to have a negative coefficient (-.009), as hypothesized: That is, the SBNR respondents were more likely to have engaged in violent crimes than their RAS peers but not the RBNS (-.002). Also, there was no significant difference in violent criminal offending between the SBNR and the NRNS (-.001). Although these findings tend to be consistent with the results from estimating group differences without controlling for the sociodemographic variables (see table 1), only one of the three hypothesized group differences was found to be significant.

Next, six intermediate models (models 1 to 6) show whether the religious/spiritual dummy variables' coefficients change not only in the size but also in significance as explanatory variables were added to the baseline model one at a time. The first two intermediate models show that the coefficient size of RAS reduced in absolute value, becoming nonsignificant, when religious involvement (33 percent reduction from $|-.009|$ to $|-.006|$ ) and low self-control (22 percent reduction from $|-.009|$ to $|-.007|)$ were added each to the baseline model. These indicate the two variables' 


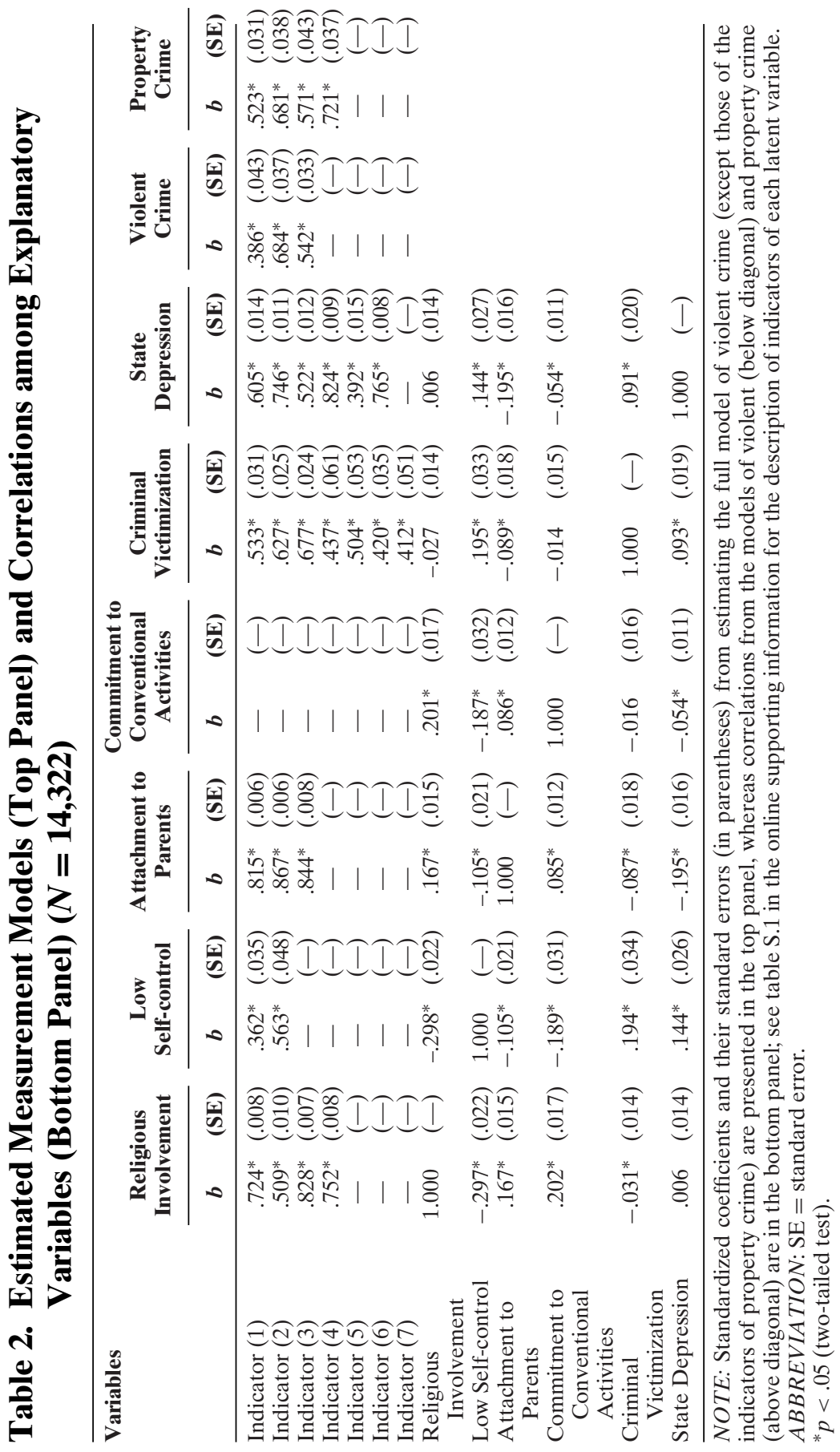




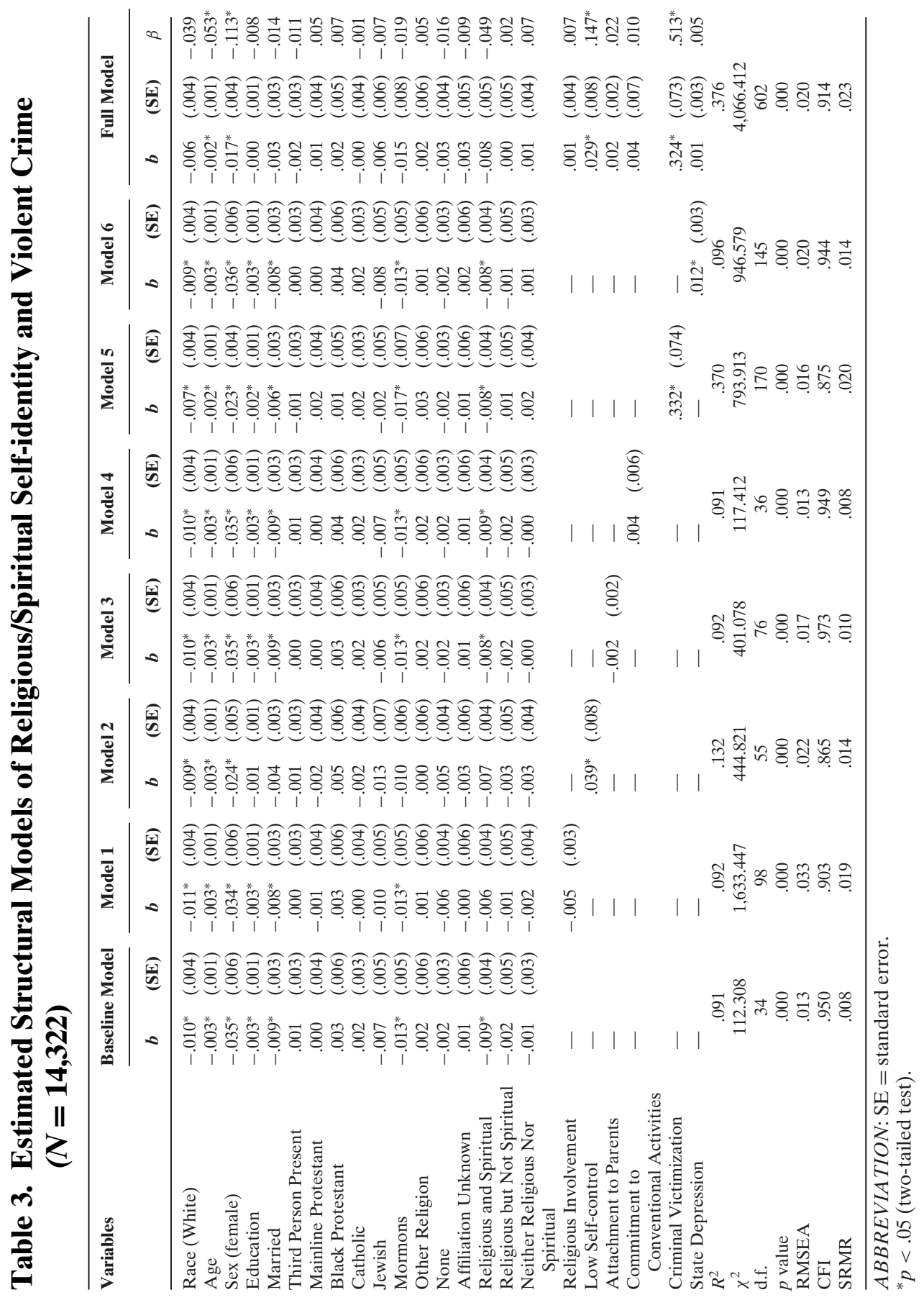


significant explanation of the observed difference in violent crime between the SBNR and the RAS as hypothesized (hypothesis 2), whereas the other explanatory variables failed to account for the SBNR-RAS difference (see models 3 to 6). That is, the SBNR were more likely to commit violent crime than the RAS partly because the former tend to have lower levels of religious involvement and self-control. The full model that includes all six variables shows the RAS coefficient reduced by 11 percent, from -.009 to -.008 , and became nonsignificant. On the other hand, differences between the SBNR and the other two groups, found to be nonsignificant in the baseline model (-.002 and -.001), remained so across the intermediate and full models.

In sum, the overall results provide partial support for our hypotheses. First, as expected, SBNR was more likely to engage in violent crime than RAS, but it was not significantly different from RBNS and NRNS. Second, we found that only one third of our hypothesized variables (religious involvement and low self-control) significantly explained the observed SBNR-RAS difference. Although it failed to explain the difference, the strain of criminal victimization had a stronger relationship with violent criminal offending ( $\beta=.513$; see the full model) and explained it more than any other explanatory variable, including religious/spiritual self-identity, in the model $\left(\Delta R^{2}\right.$ of $.279=.370$ to .091 compared with $\Delta R^{2}$ of $.285=.376$ to .091 for all six variables combined).

Turning to property crimes, table 4 presents structural models estimated in the same way as the models of violent crime. The baseline model shows empirical support for hypothesis 1 not only for the hypothesized differences involving the "religious" groups (-.048 and -.040) but also for the difference involving the "neither" group (-.036). That is, SBNR respondents were more likely to report property crimes than their NRNS peers as well as the "religious" ones. The next six models, however, show no support for the second hypothesis. Specifically, the three coefficients of group difference remained significant across the models as we entered the explanatory variables, whether one at a time (models 1 to 6) or simultaneously (full model), whereas the size of coefficients somewhat reduced: RAS (e.g., 17 percent, from $|-.048|$ to $|-.040|$ in model 1), RBNS (e.g., 10 percent, from $|-.040|$ to $|-.036|$ in model 1 and the full model), and NRNS (e.g., 11 percent, from $|-.036|$ to $|-.032|$ in models 5 and 6 ).

In sum, we found full support for the first hypothesis with respect to property crimes. As expected, the SBNR respondents were more likely to commit the crimes than the RAS and RBNS counterparts, and they were found to be different from the NRNS in the same direction as the "religious" groups. In contrast, we found no support for the second hypothesis. That is, the variables of self-control, social bonding, and general strain theory failed to explain the observed group differences. In addition, the six 


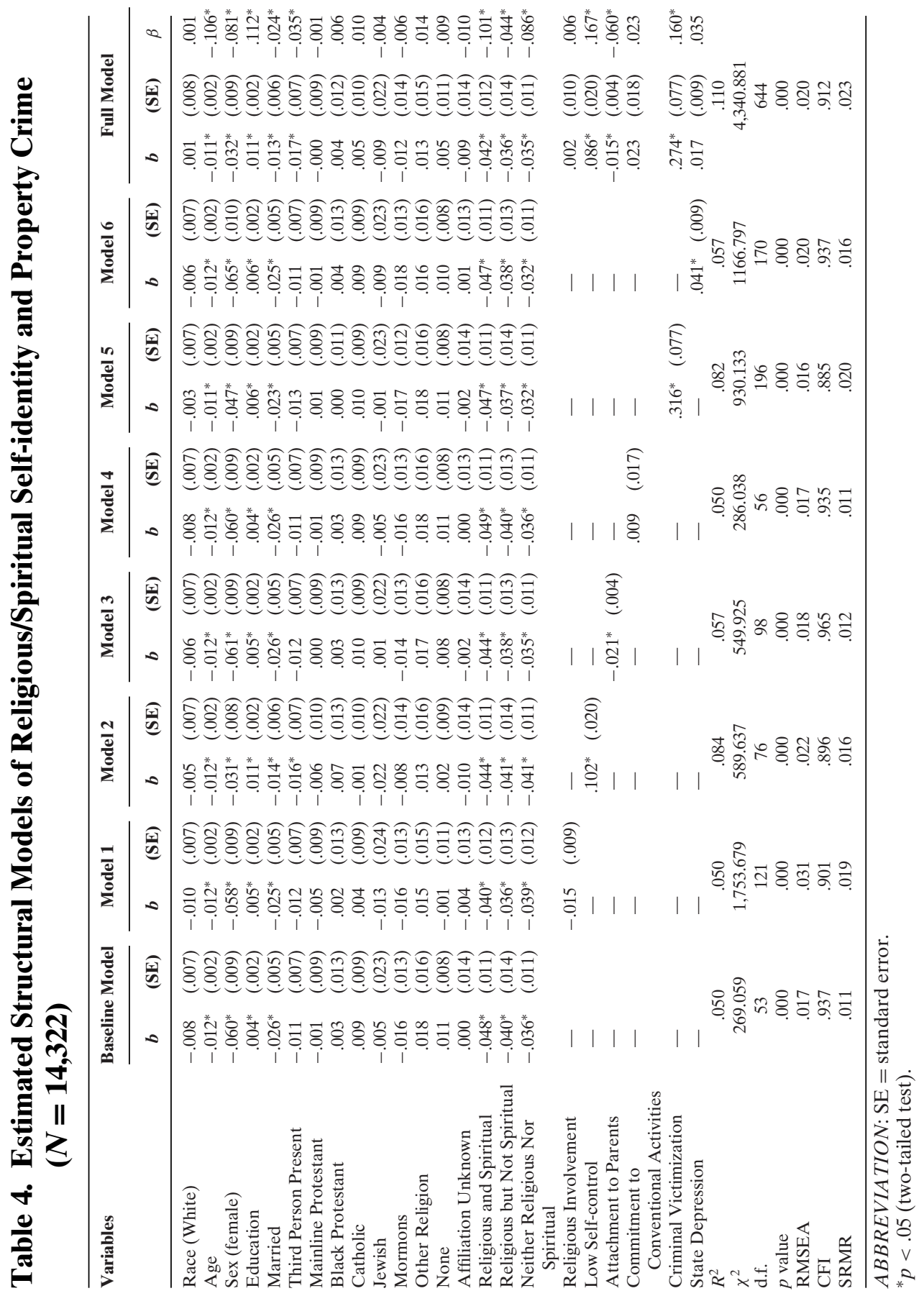


explanatory variables jointly explained property criminal offending $\left(\Delta R^{2}\right.$ of $.060=.110$ to .050$)$ less than a quarter (21 percent) of what they did for violent offending $\left(\Delta R^{2}\right.$ of $.285=.376$ to .091$)$. This limited explanation might be partly because of the data constraints that did not allow us to include other theoretical variables relevant to property crimes, especially those of social learning (Akers, 1998), like association with deviant peers, which was expected to have substantial influence on behaviors during emerging adulthood (Warr, 1998). ${ }^{9}$

\section{DISCUSSION AND CONCLUSION}

Although researchers of religion, health, and well-being have increasingly studied and have found utility in the "spirituality" concept as distinct from religion or religiousness (e.g., Hill and Pargament, 2003; Idler et al., 2003), criminologists have yet to add this dimension to the explanation of crime. In this context, the current study intended to examine whether individuals who say that they are "spiritual" while denying that they are "religious" differ from others in criminal propensity, focusing on emerging adulthood. Our findings tend to indicate that those respondents did not randomly choose the term "spiritual" over "religious" for self-identification and were more prone to commit violent crime than their "religiousand-spiritual" peers and property crime than their "neither" as well as "religious" counterparts. Furthermore, the difference in violent criminal offending was found to be partly a result of the spiritual-but-not-religious individuals being low on religious involvement and self-control, whereas the difference in property offending failed to be explained by the variables of religious involvement, self-control, social bonding, and general strain theory.

The overall results show that claiming to be "spiritual" explained one's criminal propensity independently of being "religious." Specifically, our finding that the "spiritual-but-not-religious" individuals were more likely to commit property crimes than their "neither" as well as "religious-butnot-spiritual" peers implies that claiming to be "spiritual" is a potential risk factor of criminal offending for emerging adults. With this in mind, should we expect the "religious-and-spiritual" individuals to be more crime

9. When we added the variable of peer drinking (see footnote 4 ) to the model, the results remained practically the same (see table S.2 in the online supporting information). Although the effect of peer drinking on violent crime was found to be significant (.005), the addition increased explained variance only by .010, from .376 to .386 . In contrast, the effect on property crime was not even significant (-.002). This weak finding for the alleged measure of social learning theory seems in line with the editor's and reviewers' concern that the peer drinking variable would not do justice to the theory. 
prone than their "religious-but-not-spiritual" counterparts? No. In fact, we found the former to be more conventional (religious involvement and social bonds) relative to the latter. ${ }^{10}$ This is because, as we suggested, self-claimed spirituality is dualistic in meaning. Claiming to be "spiritual" while being "religious" is denied as a risk factor for deviance if the claim connotes unorthodox or "deviant" à la Merton (1938) and antireligious beliefs and attitudes (Marler and Hadaway, 2002; Zinnbauer et al., 1997). It is, however, a protective factor when it is accompanied by claiming to be "religious," indicating an interest in and striving for the private dimension of faith-such as self-transcendence and "ultimate concerns," including life's meaning and purpose (Emmons, 2005).

To test this conceptual dualism of self-claimed spirituality in relation to criminal behavior, we conducted two supplemental analyses. First, we replaced the "religious" and "spiritual" dummy variables with the original items of self-claimed religiousness and spirituality as continuous measures. The results showed that neither the continuous measures nor their interaction term was significant, although the replacement, in general, did not affect the relationships between the explanatory variables and criminal offending in terms of significance (see tables S.3 and S.4 in the online supporting information). This indicates that our dichotomous measure of selfclaimed spirituality, consistent with the concept's dualism, was more construct valid than its continuous counterpart.

Second, we constructed an alternative $2 \times 2$ typology of religious/spiritual identity by reclassifying "slightly religious" and "slightly spiritual" as "religious" and "spiritual" rather than not, coding only the "not at all" category as "not religious" and "not spiritual." Then, we reestimated models using alternative dummy variables based on the reconstructed typology to determine whether this operationalization would generate the identity concept's measure that had higher construct validity than what we had employed. The results from estimating the alternative models of both violent and property crimes showed no significant difference between the spiritualbut-not-religious group and its comparison groups (see tables S.5 and S.6 in the online supporting information). That is, the alternative typology failed to reflect a more construct-valid measure of religious/spiritual identity than the original.

10. We reestimated group differences in the explanatory variables as well as violent and property crimes, using the religious-and-spiritual group as the reference category to compare directly with the religious-but-not-spiritual group. The latter was found to be lower than the former on religious involvement (-.326) and commitment to conventional activities (-.159) but higher on low self-control (.061). They were, however, not significantly different in attachment to parents, criminal victimization, negative emotions, and violent and property crimes. 
A closer observation revealed that the reclassification resulted in more changes in the religious-and-spiritual and neither-religious-nor-spiritual categories than the other two. Specifically, the proportion of the religiousand-spiritual respondents in the sample increased by .151 , from .379 to .530 (40 percent increase), whereas that of the neither-religious-nor-spiritual decreased by .137 , from .438 to .301 (31 percent decrease). In contrast, the religious-but-not-spiritual and the spiritual-but-not-religious groups increased ( 9 percent, from .068 to .074 ) and decreased ( 9 percent, from .115 to .105), to a lesser extent. In sum, the alternative typology had classified more respondents as being "religious," whether "spiritual" as well or not, and fewer as being "spiritual but not religious" or "neither religious nor spiritual." This more lenient classification of respondents as being "religious" and more strict classification of those as being "spiritual" eliminated the significant group differences in violent and property offending observed previously, and thus, the original typology seems to be better than the alternative in terms of its resultant measure's construct validity. Furthermore, a contingency table analysis showed no significant (positive) relationship between the two typologies (chi-square $=16.742$, degrees of freedom [d.f.] $=$ $9, p=.369$ ), indicating that they were not even remotely similar.

Although not related to our hypothesis testing, an interesting observation was that only one third of the "neither" group had no religious affiliation (36.13 percent), whereas most of them reported they were either Protestant (30.81 percent)—evangelical (14.28 percent), mainline (11.08 percent), Black Protestant (5.45 percent) —or Catholic (24.19 percent), with still others reporting their affiliation as Jewish (.79 percent), Mormon (.49 percent), other (3.20 percent), or unknown (4.41 percent). Thus, for emerging adults, being "neither religious nor spiritual" is unlikely to be coterminous with whether they have a religious affiliation.

The current study is the first ever conducted to examine the relationship between self-claimed spirituality as well as religiousness and criminal behaviors, so future research should replicate our study not only for emerging adulthood but also for other stages of life. When replicated, panel data with short intervals would be best to establish causal ordering between the self-identity and criminal offending, which we could not show with crosssectional data. Also, although we included in our model variables reflecting self-control, social bonding, and general strain theory as explanations of the differences between the "spiritual but not religious" and other groups, some key predictors of crime, especially social learning variables, could not be included in our analysis. Future research should examine whether our limited explanation of the group differences is partly a result of the omission of key criminological variables.

Despite these limitations, the current study has a potential contribution to criminology not only because it reports empirical evidence of a concept 
prior research has largely ignored (i.e., spirituality as distinct from religiousness) but also because it points to "a new criminological perspective that focuses on human personhood (i.e., moral, believing animal), motivation, and action, which often has been neglected by modern criminology under the influence of the naturalistic, utilitarian, and noncultural tradition of Western social theory (Smith, 2003)" (Johnson and Jang, 2010: 129). Unlike criminologists and sociologists, other social scientists, especially psychologists, have examined a broadly redefined concept of religion, often called "spirituality," finding the concept to be significantly related to human behaviors, independent of religiousness (Emmons, 2005; Hill and Pargament, 2003; Miller and Thoresen, 2003; Wong, 2012). The new concept is unlikely to trump the key, more proximate causes of crime (e.g., control and strain variables) in the relative strength of "direct" explanation as implied by the current findings, but it is likely to enhance our understanding of crime causation as it not only adds more explanation, although perhaps mostly indirect via the proximate causes, but also conditions relationships between the proximate causes and crime. Thus, future research on the new "spirituality" concept has a potential to contribute to the development of "a systematic criminology of religion," which Cullen (2010: 158) recently called for, suggesting the "study of religion should be an integral part of the criminological enterprise and a vibrant subfield within our discipline."

In conclusion, is being "spiritual" enough to reduce criminal propensity without also being religious? Our study suggests the answer is no-at least during emerging adulthood. That is, being "spiritual" without being religious was found to be positively, rather than negatively, associated with the probability of engaging in violent and, to a greater extent, property crimes. In contrast, consistent with prior research on religion and crime (Johnson and Jang, 2010), being religious was inversely related to criminal offending whether or not in conjunction with being "spiritual." Thus, according to the current study, it would be a mistake to treat the term "spiritual" as criminologically synonymous with "religious" given that they are likely to connote different beliefs and attitudes.

\section{REFERENCES}

Agnew, Robert. 2006. Pressured into Crime: An Overview of General Strain Theory. Los Angeles, CA: Roxbury.

Akers, Ronald L. 1998. Social Learning and Social Structure: A General Theory of Crime and Deviance. Boston, MA: Northeastern University Press. 
Arnett, Jeffrey J. 2000. Emerging adulthood: A theory of development from the late teens through the twenties. American Psychologist 55:469-80.

Arnett, Jeffrey J. 2005. The developmental context of substance use in emerging adulthood. Journal of Drug Issues 35:235-53.

Baier, Colin J., and Bradley R. E. Wright. 2001. "If you love me, keep my commandments": A meta-analysis of the effect of religion on crime. Journal of Research in Crime and Delinquency 38:3-21.

Baker, Joseph O., and Buster G. Smith. 2009. The nones: Social characteristics of the religiously unaffiliated. Social Forces 87:1251-63.

Baraldi, Amanda N. and Kraig K. Enders. 2010. An introduction to modern missing data analyses. Journal of School Psychology 48:5-37.

Chantala, Kim. 2006. Guidelines for Analyzing Add Health Data. Chapel Hill: Carolina Population Center, University of North Carolina at Chapel Hill.

Chatters, Linda M., Robert Joseph Taylor, Kai M. Bullard, and James S. Jackson. 2008. Spirituality and subjective religiosity among African Americans, Caribbean Blacks, and non-Hispanic Whites. Journal for the Scientific Study of Religion 47:725-37.

Cullen, Francis T. 2010. Toward a criminology of religion: Comment on Johnson and Jang. In Contemporary Issues in Criminological Theory and Research: The Role of Social Institutions, eds. Richard Rosenfeld, Kenna Quinet, and Crystal Garcia. Belmont, CA: Wadsworth.

Dougherty, Kevin D., and Sung Joon Jang. 2008. Spirituality: Religion and spirituality are not mutually exclusive. In What Americans Really Believe, ed. Rodney Stark. Waco, TX: Baylor University Press.

Emmons, Robert A. 2005. Striving for the sacred: Personal goals, life meaning, and religion. Journal of Social Issues 61:731-45.

Fuller, Robert C. 2001. Spiritual, but Not Religious: Understanding Unchurched America. New York: Oxford University Press.

Gallup, George H., Jr. 2003. Americans' Spiritual Searches Turn Inward. http://www.gallup.com/poll/7759/americans-spiritual-searches-turninward.aspx.

Garelli, Franco. 2007. Research note between religion and spirituality: New perspectives in the Italian religious landscape. Review of Religious Research 48:318-26. 
Giordano, Peggy C., Monica A. Longmore, Ryan D. Schroeder, and Patrick M. Seffrin. 2008. A life-course perspective on spirituality and desistance from crime. Criminology 46:99-132.

Good, Marie, Teena Willoughby, and Michael A. Busseri. 2011. Stability and change in adolescent spirituality/religiosity: A person-centered approach. Developmental Psychology 47:538-50.

Gottfredson, Michael R., and Travis Hirschi. 1990. A General Theory of Crime. Stanford, CA: Stanford University Press.

Graham, John W. 2009. Missing data analysis: Making it work in the real world. Annual Review of Psychology 60:549-76.

Harris, Kathleen M., Carolyn T. Halpern, Eric Whitsel, Jon M. Hussey, Joyce Tabor, Pamela Entzel, and J. R. Udry. 2009. The National Longitudinal Study of Adolescent Health: Research Design. Chapel Hill: Carolina Population Center, University of North Carolina at Chapel Hill.

Harrold, Philip. 2006. Deconversion in the emerging church. International Journal for the Study of the Christian Church 6:79-90.

Hill, Peter C., and Kenneth I. Pargament. 2003. Advances in the conceptualization and measurement of religion and spirituality-implications for physical and mental health research. American Psychologist 58:64-74.

Hill, Peter C., Kenneth I. Pargament, Ralph W. Hood, Michael E. McCullough, James P. Swyers, David B. Larson, and Brian J. Zinnbauer. 2000. Conceptualizing religion and spirituality: Points of commonality, points of departure. Journal for the Theory of Social Behaviour 30:51-77.

Hirschi, Travis. 1969. Causes of Delinquency. Berkeley: University of California Press.

Hirschi, Travis, and Rodney Stark. 1969. Hellfire and delinquency. Social Problems 17:202-13.

Hodge, David R., Kathleen Andereck, and Harry Montoya. 2007. The protective influence of spiritual-religious lifestyle profiles on tobacco use, alcohol use, and gambling. Social Work Research 31:211-9.

Hodge, David R., Paul Cardenas, and Harry Montoya. 2001. Substance use: Spirituality and religious participation as protective factors among rural youths. Social Work Research 25:153-61. 
Hu, Li-tze and Peter M. Bentler. 1999. Cutoff criteria for fit indexes in covariance structure analysis: Conventional criteria versus new alternatives. Structural Equation Modeling 6:1-55.

Idler, Ellen L., Marc A. Musick, Christopher G. Ellison, Linda K. George, Neal Krause, Marcia G. Ory, Kenneth I. Pargament, Lynda H. Powell, Lynn G. Underwood, and David R. Williams. 2003. Measuring multiple dimensions of religion and spirituality for health research: Conceptual background and findings from the 1998 general social survey. Research on Aging 25:327-65.

Jang, Sung Joon, and Jeremy R. Rhodes. 2012. General strain and nonstrain theories: A study of crime in emerging adulthood. Journal of Criminal Justice 40:176-86.

Johnson, Byron R., and Sung Joon Jang. 2010. Crime and religion: Assessing the role of the faith factor. In Contemporary Issues in Criminological Theory and Research: The Role of Social Institutions, eds. Richard Rosenfeld, Kenna Quinet, and Crystal Garcia. Belmont, CA: Wadsworth.

King, Michael, Louise Marston, Sally McManus, Terry Brugha, Howard Meltzer, and Paul Bebbington. 2013. Religion, spirituality and mental health: Results from a national study of English households. British Journal of Psychiatry 202:68-73.

Koenig, Laura B., Matt McGue, and William G. Iacono. 2008. Stability and change in religiousness during emerging adulthood. Developmental Psychology 44:532-43.

Laub, John H., and Robert J. Sampson. 2003. Shared Beginnings, Divergent Lives: Delinquent Boys to Age 70. Cambridge, MA: Harvard University Press.

Lim, Chaeyoon, Carol A. MacGregor, and Robert D. Putnam. 2010. Secular and liminal: Discovering heterogeneity among religious nones. Journal for the Scientific Study of Religion 49:596-618.

Marler, Penny Long, and C. Kirk Hadaway. 2002. "Being religious" or "being spiritual" in America: A zero-sum proposition? Journal for the Scientific Study of Religion 41:289-300.

Merton, Robert K. 1938. Social structure and anomie. American Sociological Review 3:672-82. 
Miller, Alan. 2012. "My take: 'I'm spiritual but not religious' is a cop-out." http://religion.blogs.cnn.com/2012/09/29/my-take-im-spiritual-notreligious-is-a-cop-out/.

Miller, William R., and Carl E. Thoresen. 2003. Spirituality, religion, and health—an emerging research field. American Psychologist 58:24-35.

Muthén, Bengt O. 1983. Latent variable structural equation modeling with categorical data. Journal of Econometrics 22:43-65.

Muthén, Linda K. and Bengt O. Muthén. 1998-2012. Mplus User's Guide, 7th ed. Los Angeles, CA: Muthén \& Muthén.

Pargament, Kenneth I. 1997. The Psychology of Religion and Coping: Theory, Research, Practice. New York: Guilford Press.

Pepper, Miriam, Tim Jackson, and David Uzzell. 2010. A study of multidimensional religion constructs and values in the United Kingdom. Journal for the Scientific Study of Religion 49:127-46.

Pew Research Center. 2010. Religion Among the Millennials: Less Religiously Active Than Older Americans, But Fairly Traditional In Other Ways. http://www.pewforum.org/age/religion-among-the-millennials. aspx.

Piedmont, Ralph L. 1999. Does spirituality represent the sixth factor of personality? Spiritual transcendence and the five-factor model. Journal of Personality 67:985-1013.

Piedmont, Ralph L., Anna T. Ciarrochi, Gabriel S. Dy-Liacco, and Joseph E. G. Williams. 2009. The empirical and conceptual value of the spiritual transcendence and religious involvement scales for personality research. Psychology of Religion and Spirituality 1:162-79.

Piquero, Alex R., Robert Brame, Paul Mazerolle, and Rudy Haapanen. 2002. Crime in emerging adulthood. Criminology 40:137-70.

Roof, Wade Clark. 1993. A Generation of Seekers: The Spiritual Journeys of the Baby Boom Generation. San Francisco, CA: HarperSanFrancisco.

Roof, Wade Clark. 1999. Spiritual Marketplace: Baby Boomers and the Remaking of American Religion. Princeton, NJ: Princeton University Press.

Sampson, Robert J., and John H. Laub. 1993. Crime in the Making: Pathways and Turning Points through Life. Cambridge, MA: Harvard University Press. 
Sampson, Robert J., and John H. Laub. 1996. Socioeconomic achievement in the life course of disadvantaged men: Military service as a turning point, circa 1940-1965. American Sociological Review 61:347-67.

Saucier, Gerard, and Katarzyna Skrzypinska. 2006. Spiritual but not religious? Evidence for two independent dispositions. Journal of Personality 74:1257-92.

Schlehofer, Michele M., Allen M. Omoto, and Janice R. Adelman. 2008. How do "religion" and "spirituality" differ? Lay definitions among older adults. Journal for the Scientific Study of Religion 47:411-25.

Simmel, Georg. 1997. Essays on Religion. New Haven, CT: Yale University Press.

Smith, Christian. 2003. Moral, Believing Animals: Human Personhood and Culture. New York: Oxford University Press.

Smith, Christian. 2005. Soul Searching: The Religious and Spiritual Lives of American Teenagers. New York: Oxford University Press.

Smith, Christian. 2009. Souls in Transition: The Religious and Spiritual Lives of Emerging Adults. New York: Oxford University Press.

Steensland, Brian, Jerry Park, Mark D. Regnerus, Lynn Robinson, W. B. Wilcox, and Robert Woodberry. 2000. The measure of American religion: Toward improving the state of the art. Social Forces 79: 291-318.

Storm, Ingrid. 2009. Halfway to heaven: Four types of fuzzy fidelity in Europe. Journal for the Scientific Study of Religion 48:702-18.

Uecker, Jeremy E., Mark D. Regnerus, and Margaret L. Vaaler. 2007. Losing my religion: The social sources of religious decline in early adulthood. Social Forces 85:1667-92.

Uggen, Christopher. 2000. Work as a turning point in the life course of criminals: A duration model of age, employment, and recidivism. American Sociological Review 65:529-46.

Underwood, Lynn G., and Jeanne A. Teresi. 2002. The daily spiritual experience scale: Development, theoretical description, reliability, exploratory factor analysis, and preliminary construct validity using health-related data. Annals of Behavioral Medicine 24:22-33.

Warr, Mark. 1998. Life-course transitions and desistance from crime. Criminology 36:183-216. 
Wink, Paul, Lucia Ciciolla, Michele Dillon, and Allison Tracy. 2007. Religiousness, spiritual seeking, and personality: Findings from a longitudinal study. Journal of Personality 75:1051-70.

Wink, Paul, and Michele Dillon. 2003. Religiousness, spirituality, and psychosocial functioning in late adulthood: Findings from a longitudinal study. Psychology of Religion and Spirituality 18:916-24.

Wong, Paul T. P. 2012. The Human Quest for Meaning: Theories, Research, and Applications. New York: Routledge.

Wuthnow, Robert. 1998. After Heaven: Spirituality in America since the 1950s. Berkeley: University of California Press.

Zinnbauer, Brian J., Kenneth I. Pargament, Brenda Cole, Mark S. Rye, Eric M. Butter, Timothy G. Belavich, Kathleen M. Hipp, Allie B. Scott, and Jill L. Kadar. 1997. Religion and spirituality: Unfuzzying the fuzzy. Journal for the Scientific Study of Religion 36:549-64.

Zinnbauer, Brian J., Kenneth I. Pargament, and Allie B. Scott. 1999. The emerging meanings of religiousness and spirituality: Problems and prospects. Journal of Personality 67:889-919.

Zwissler, Laurel. 2007. Spiritual, but religious: "Spirituality" among religiously motivated feminist activists. Culture and Religion 8:51-69.

Sung Joon Jang is an associate professor of sociology and a distinguished senior fellow in the program on prosocial behavior in the Institute for Studies of Religion at Baylor University. His research focuses on the effects of family, school, peers, religion, and spirituality on crime and deviance. Recent publications have appeared in Journal of Criminal Justice, Deviant Behavior, Youth \& Society, and Sociological Focus. He is coprincipal investigator on a longitudinal study examining the long-term effectiveness of seminary programs in maximum security prisons.

Aaron B. Franzen is a $\mathrm{PhD}$ candidate in the Department of Sociology at Baylor University. His research focuses on links between sociology of religion and personal identity, criminology, and more recently, the interaction between physicians and patients. His recent study on the impact that the relationship among identity, context, and Bible reading has on moral and political views is forthcoming in Review of Religious Research. 


\section{SUPPORTING INFORMATION}

Additional Supporting Information may be found in the online version of this article at the publisher's web site:

Table S.1. Items Used for Analysis

Table S.2. Estimated Structural Models of Religious/Spiritual Self-identity and Violent/Property Crime: Peer Drinking Included $(n=14,322)$

Table S.3. Estimated Structural Models of Religious/Spiritual Self-identity (as continuous) and Violent Crime $(n=14,322)$

Table S.4. Estimated Structural Models of Religious/Spiritual Self-identity (as continuous) and Property Crime $(n=14,322)$

Table S.5. Estimated Structural Models of Religious/Spiritual Self-identity (Alternative Measure) and Violent Crime $(n=14,322)$

Table S.6. Estimated Structural Models of Religious/Spiritual Self-identity (Alternative Measure) and Property Crime $(n=14,322)$ 